\title{
Saúde, Trabalho e Terapia Ocupacional, uma relação indissociável
}

\author{
Selma Lancman' ${ }^{1}$ Juliana de Oliveira Barros² , Tatiana de Andrade Jardim³, \\ Elisabete Ferreira Mângia ${ }^{4}$
}

Apresentamos aos nossos leitores mais um fascículo da Revista de Terapia Ocupacional da USP. Trata-se do Dossiê Temático "Terapia Ocupacional, Saúde e Trabalho: perspectivas e desafios" que conta com a colaboração de docentes pesquisadores, pós-graduandos e alunos de graduação das principais instituições de pesquisa e ensino do Brasil.

A escolha dessa temática está relacionada ao I Colóquio Brasileiro de Terapia Ocupacional, Saúde e Trabalho, ocorrido em maio de 2016 e ao reconhecimento da importância desse campo na Terapia Ocupacional contemporânea.

As evidências atuais comprovam os efeitos prejudiciais do trabalho na saúde e suas consequências no aumento dos adoecimentos e crescentes afastamentos do trabalho. Além disso, atestam os obstáculos e dificuldades encontrados por profissionais e trabalhadores nos processos de retorno e permanência no trabalho, em especial após períodos longos de afastamento. Nesse contexto a atuação da Terapia Ocupacional tem sido reconhecida, ampliada e complexificada.

As ações de saúde e reabilitação no campo da saúde e trabalho tem caráter sistêmico e nelas a promoção e prevenção à saúde no trabalho, a atenção aos trabalhadores adoecidos, a reabilitação profissional, o retorno e a permanência no trabalho devem ser consideradas etapas de um processo único e indissociável, no qual o conteúdo do trabalho, as condições nas quais ele é exercido e sua organização devem ser constantes alvos de ação.

Essa indissociabilidade é confirmada pelas novas políticas de saúde instituídas nesse campo, tal como a Política Nacional de Segurança e Saúde no Trabalho - PNSST (MS, 2011) e a Rede Intersetorial de Reabilitação Integral (MPS, 2016) que busca implementar a Rede Intersetorial de Reabilitação Integral, composta por ações integradas e articuladas entre serviços e ações do conjunto das Políticas de Saúde, Previdência Social, Trabalho, Assistência Social, Educação, dentre outras.

Ressalta-se também que o trabalho deve ser considerado um aspecto transversal no conjunto das práticas desenvolvidas pela Terapia Ocupacional em todas as suas áreas de atuação. Para os indivíduos, trabalhar é se engajar, é participar do mundo, é se inserir em redes sociais, é constituir-se a si próprio. É no trabalho e por meio dele que os indivíduos produzem e reproduzem sua contratualidade, exercitam sua cidadania e inclusão social. A fragilidade das possibilidades de acesso e engajamento no trabalho tendem á levar os indivíduos e grupos sociais e viverem situações de vulnerabilidade e desfiliação social. Nessa direção este fascículo busca trazer aos leitores contribuições que refletem a importância do tema saúde e trabalho e sua relevância para as práticas de pesquisa, ensino e assistência em Terapia Ocupacional.

Apresentamos com destaque neste fascículo a entrevista inédita com o Prof. Christophe Dejours, do Conservatoire National des Arts et Metiers, França, intitulada a "Centralidade do trabalho para a construção da saúde" e a tradução de um importante material sobre um programa de retorno e permanecia no trabalho: "Guia para um programa de práticas integradas para apoiar o retorno ao trabalho e a promoção da permanência no emprego", elaborado pela Profa. Louise St-Arnaud, da Universidade de Laval, no Canadá.

Essas duas publicações evidenciam a centralidade do trabalho, as relações dele decorrentes na vida das pessoas e na construção da sua saúde. Enfatizam também a importância da cooperação, do reconhecimento do fazer, da organização do trabalho, de seu conteúdo e do próprio trabalhar, considerando a relação indissociável entre quem trabalha e o que se produz.

1. Profa.Titular do Departamento de Fisioterapia, Fonoaudiologia e Terapia Ocupacional da Faculdade de Medicina da USP. Email: lancman@usp.br

2. Terapeuta Ocupacional do Departamento de Fisioterapia, Fonoaudiologia e Terapia Ocupacional da Faculdade de Medicina da USP, doutora em Ciências da reabilitação pela FMUSP. Email: juliana.obarros@usp.br

3. Terapeuta Ocupacional do Departamento de Fisioterapia, Fonoaudiologia e Terapia Ocupacional da Faculdade de Medicina da USP, doutora em Ciências da reabilitação pela FMUSP. Email: tati.ajardim@usp.br.

4. Profa. do Departamento de Fisioterapia, Fonoaudiologia e Terapia Ocupacional da Faculdade de Medicina da USP, Editora da Revista de Terapia Ocupacional da Universidade de São Paulo. Email: mangeli@usp.br 
Neles de pode compreender a relevância do trabalho e seu lugar na constituição das identidades e pertencimento social.

Nessa direção, o fazer e os desafios engendrados no seu exercício, a visibilidade dos aspectos subjetivos mobilizados no ato de trabalhar e dos esforços de cada um para produzir e contribuir com o seu saber-fazer na construção do mundo, situa o trabalho como o principal contexto da vida dos indivíduos, que possibilita o exercício coletivo da democracia.

Trabalhar significa também pensar, conviver, agir, construir-se a si próprio e confrontar-se com as dificuldades do real do trabalho.

O sofrimento vivenciado no trabalho é inerente aos desafios advindos do seu exercício e não será necessariamente adoecedor, ao contrário, dependendo das condições que o trabalhador tem de superá-lo poderá ser fator de crescimento, de desenvolvimento psíquico e de emancipação. Trabalhar, para além dos ganhos financeiros, significa participar da vida social, promover a identificação com aquilo que se faz, a realização de si. Em suma, o trabalho é um elemento central na construção da saúde.

Esperamos que esse dossiê estimule outras publicações assemelhadas de forma a assegurar a continuidade do debate. Agradecemos a todos que colaboraram com esse número e, em especial, ao Prof. Christophe Dejours pela entrevista e à Profa. Louise st-Arnaud que gentilmente cedeu o direito de tradução do Guia. 